\title{
THE PAST AND FUTURE OF CLIMATE-RELATED SERVICES IN THE UNITED STATES
}

\author{
Stanley A. Changnon
}

Illinois State Water Survey

Champaign, IL

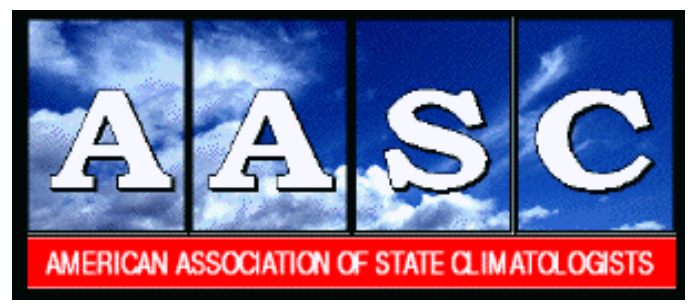

2007

Journal of Service Climatology

Volume 1, Number 1, Pages 1-7

A Refereed Journal of the American Association of State Climatologists 


\title{
The Past and Future of Climate-Related Services in the United States
}

\author{
Stanley A. Changnon \\ Illinois State Water Survey \\ 2204 Griffith Drive \\ Champaign, Illinois 61820
}

Editor's Note: This was an invited review paper on the state of service climatology.

\begin{abstract}
Climate information has been the foundation upon which the nation's weather-sensitive activities and infrastructure have been developed over the past 200 years. By 1970, climate services had begun to move to a new level of recognition and ever higher value to the climate-sensitive sectors of the nation. The past four decades have seen a series of scientific advances and technological changes that have vastly enhanced the provision of climate information. Atmospheric scientists created major improvements in weather-sensing instruments, in data quality and its archival, in the ease of accessing data and climate information, and in the generation of user-friendly climate products. Coupled with these advances have been national and global economic conditions and government policies that have acted to greatly increase the demand for climate products. On the government side, there has been establishment of state climatologists in all states, a national network of six regional climate centers, and an enhanced national data center. On the business side, there has been a rapid expansion into climatology, bringing new climate-based products and services to a vast array of climate-sensitive businesses and government agencies. However, not all aspects of climate services are at an optimum level. Five limitations need future attention to achieve optimum usage of climate information: better climate training; stabilization of weather/climate measurements; enhanced outreach to users; better information on climate impacts; and knowledge of effects of climate change. Regardless, provision of climate data and information is the oldest atmospheric sciences activity in service to society and its most successful.
\end{abstract}

\section{Introduction}

I have drawn upon 55 years of personal involvement in climate services and applied research to prepare this historical and future perspective on climate services. My past and future assessments are based on my background experiences and notable achievements of others. My background has included assessments of all types of climate impacts (economic, physical, and societal); work on statistical-based predictions; development of designoperational criteria for agriculture, hydrology, and construction; and climate risk analysis.

I began as the staff climatologist for the Illinois State Water Survey in 1952 and continued in that role for 20 years. I then served as the Illinois State Climatologist for 10 more years. These 30 years involved provision of climate services-a continual provision of climate data and information to a diverse user community. I designed the regional climate center concept, formed the first center, and helped get a national network of centers established. I have been a long-term consultant to private companies interested in climate information. I promoted state and federal legislation to enhance climate services, and I have served as a climate consultant to state and the federal governments, and to foreign governments including Israel, Morocco, and Thailand. I helped establish the AASC in 1976 with a key commitment to services, and I served as president in 1980-1981 (Changnon 1981). I had the good fortune to know and work with Helmut Landsberg for $20+$ years, and I consider him to be the true pioneer and crusader for climate services in the U.S. during the $20^{\text {th }}$ century. Hopefully, my background has been sufficient to develop an adequate and accurate perspective on past events and future issues involving climate services.

\section{Dimensions of Service-driven Climatological Activities}

Climatological information has been the foundation upon which the world's weathersensitive activities and infrastructure have been developed. Applications of climate data and information have likely contributed more to the development of most nations than any other function of the atmospheric sciences. Today, weather forecasts are very useful and important but these only became available in the $20^{\text {th }}$ century, more than 150 years after climatology had been in service to the nation. 
Climate services are a part of applied climatology. Activities falling under the umbrella of service-driven applied climatology are spread among many disciplines. The activities also have interfaces with many parts of the atmospheric sciences, forming a myriad number of interactions. The field is truly interdisciplinary, embracing climatologists and those of most other disciplines including hydrology, agriculture, engineering, and business. This breath of activities and their evolution over time, makes the history of climatology in providing services interesting. Over 50 years ago, two leaders in the field defined applied climatology as the scientific analysis of climate data in light of a useful application for an operational purpose (Landsberg and Jacobs 1951).

My interpretation is that services-oriented applied climatology describes, defines, interprets, and explains the relationships between climate conditions and countless weather-sensitive activities. For example, if viewed in a business sense, climatology embraces interactions with marketing, sales, customer services, research support, and the delivery arm for climatological data and information. The diversity of the field is one of its hallmarks.

Service-oriented climatology also embraces fundamental, basic studies of the climate system so as to describe event causation as a functional part of explaining climatic relationships to other phenomena. For example, a climatological study of rainfall effects on streamflow may include an explanation of the atmospheric factors influencing the rainfall variability between days, months, or years.

Service-oriented climatological endeavors have evolved over the past 60 years around two functional areas. First, is the inner core of climatology, focusing on instruments and data. Functions include data collection, data quality assessment, data transmission, data archival, assessment of data's representativeness in space and time, and access to data.

The other functional area relates to the interpretation of data and generation of climate information generally based on interactions with users. Activities include statistical and physical analyses, performance of special interpretive studies, and generation of information (published or computer based). Within the atmospheric sciences, service-driven climatology also extends into the areas of dynamic climatology and instrumentation. Research develops the informational products for the users, studies the climate-sector relationships, develops statistical techniques to express climate information effectively, contributes to weather data collection efforts, and develops databases to fulfill its mission.

Today, these functions are handled by state climatologists; university-based scientists; and staffs at regional climate centers, the National Climatic Data Center, the Climate Prediction Center, and in the private sector that provides climate services. The private sector has grown rapidly in recent years for three reasons including growing economic competition among climate sensitive businesses; users have become more aware of what is available and how to use climate information; and because the property insurance industry lacked detailed records of weather losses and thus, required climate-based models of extreme storms to establish risks (Changnon 2007). The Weather Risk Management Association reported that sales of its member companies in 2004 totaled $\$ 4.2$ billion, reflecting the sizable dimensions of the private sector in climate services and the value of climate information.

Users of climate products include scientists in many disciplines and decision makers in business and government. Effective relationships between climatologists and users require a two-way interaction to share needs and information. Applications of climate information fall into four classes: 1) design of structures and planning activities 2) assessments of current and past conditions including evaluation of extreme events, 3) study of the relationships between weatherclimate conditions and those in other parts of the physical and socioeconomic worlds, and 4) operation of weather-sensitive systems that employ climatic information in making decisions.

\section{Key Past Events}

Service-oriented applied climatology, as one sector of today's world of atmospheric sciences, was the first atmospheric sciences activity to serve human kind. Climatology remains a highly successful contributor to the nation's well being.

Persons such as Thomas Jefferson were among the nation's early users of climate information. Jefferson planned farming operations around local climate conditions and used climate information in the equipment he designed, and in building construction (Martin

1952). Crop selection, construction styles, and building placement during the $18^{\text {th }}$ Century in the U.S. often reflected awareness of climate conditions and their effects.

The beginning of weather observations, both privately and at military forts, helped further the use of climate data. The expansion and organization of the nation's weather data collection system, and science in general, occurred during the $19^{\text {th }}$ Century.

Early leaders in the emerging field of meteorology, such as James Espy and Elias Loomis, recognized regional differences in the nation's climate and identified how these differences created profoundly different effects on human endeavors (Fleming 1990). A key scientist of the century, Joseph Henry, made invaluable studies in climatology, and in the 1850s analyzed the impacts of climate on U.S. agriculture of the time. Koeppen (1885) and other scientists began associating climate conditions with various land uses and plant environments as a means to define climate regions in each continent.

Further growth in the understanding of climate interactions with various physical systems, such as water resources, had to await the systematic collection of data about climate as well as weathersensitive conditions. As the nation entered the $20^{\text {th }}$ Century, data collection had been in progress sufficiently long to allow new, more definitive studies of how climate impacted activities. For example, Thiessen (1912), who was a civil engineer, defined how climate conditions were to be used in engineering designs. Famed hydrologist Robert 
Horton made basic discoveries about the components of the hydrologic cycle, and in the 1920 s he was the first to un-ravel the complexities of the climate-hydrology relationships for the Great Lakes (Horton 1927). Early key studies of effects of climate on human health and behavior included those of C.F. Brooks (1925).

A national priority of the $19^{\text {th }}$ Century was to enhance agricultural production, and this led to the establishment of the U.S. Weather Bureau in 1888, as part of the Department of Agriculture (Whitnah 1961). Establishment of experimental farms around the nation produced the weather data needed to make more definitive studies of how various components of the climate affected each crop, as well as livestock. Wallace (1920) made major advances by developing the first climate-crop yield models. Thornthwaite (1937) pioneered in the modeling of the hydrologic system so as to derive measures of evapotranspiration and soil moisture and their effects on both plants and crops.

Importantly, by 1940 many of the fundamental relationships between climate conditions and other physical systems had been sufficiently delineated to allow highly effective designs of structures, selections of regionally appropriate crop varieties, and wise management of water resource systems in the varying climatic zones of the nation (Landsberg 1946). The pressures of World War II for climate data and information brought forth a new dimension to service-oriented climatology (Jacobs 1947). For example, new studies focused on severe weather conditions, such as tornadoes and hail, and their effects on crops, property, transportation, and human life (Flora 1953). A flood of publications within the realm of applied climatology appeared during the 1940s and 1950s (Landsberg and Jacobs 1951). This explosion of research and information generation was also tied to the creation of computers during World War II and use of punch cards as a means of digitizing historical weather data. By 1948 a national center housing all historical climate data had been established. The National Climatic Center (now NCDC) staff began generating a myriad of publications giving potential users access to information never before widely available (Changnon 1981).

Ever improving computers and digitized data allowed major achievements in modeling of climate effects such as hydrologic models that related various climatic variables to streamflow behavior (Linsley et al. 1958). Heavy rainfall design information, critical to planning and designs to manage flooding, was generated (Hershfield 1961; Huff 1986). A highly useful national drought index was devised (Palmer 1965), and sophisticated climate-crop yield models appeared, allowing accurate predictions of yield outcomes well before harvest (Thompson 1964). Other studies addressed another important sector of applied climatologythe economic and environmental impacts of all forms of climate (Maunder 1970; McQuigg 1974). Major advances in statistical techniques for applied climate analysis occurred (Court 1949; Conrad and Pollack 1944). An area of climatology that has evolved over the past 100 years concerns urban climates and other human-induced changes to the landscape leading to altered local and regional climates (Landsberg 1956; Changnon 1973). The impacts of these changes on the physical world and socioeconomic sectors have also been assessed (Changnon 1984; Hare 1985) with climate guidance to urban planners (Changnon 1979). Finally, textbooks that addressed applied climatology appeared (Oliver 1973, 1981; Thompson and Perry 1997), acting to enhance training and attention to the field and its demands for knowledgeable services.

By 1970, service-driven climatology had moved to a new level of recognition and ever higher value to the user community. Atmospheric scientists within the field realized and reacted to four major improvements: 1) in weather-sensing instruments; 2) in data quality and its archival, 3) in access of data and climate information, and 4) in the generation of user-friendly climate products.

The past 35 years have seen a series of scientific and technological changes that have vastly enhanced climate services. Coupled with these advances have been national and global economic conditions that acted to increase the demand for climate products. A new era of service-driven climatology had begun.

The agricultural economy became global and with this expansion came huge economic pressures. American firms searched for every activity that would give them a competitive advantage. One of these was use of climate predictions (Changnon 1992). Firms that had previously ignored use of uncertain climate outlooks now became users (Changnon 1998). Other business sectors also became global, and the net effect was ever more use of climate data and information. These trends have greatly enhanced the private sector providing climate information (Changnon 2007).

Other factors enhancing wide interest and use of climate information were major global climate anomalies of the 1970s and early 1980s and their severe impacts (Kates 1980; Panel 1981). This included the devastating Sahel drought, the record cold winters of 1976-1980 in the U.S., and the droughts of 1980, 1983, and 1988. Climate and the problems it created, including escalation of federal relief payments for weather-climate disasters, got the attention of the federal government, and Congress passed the National Climate Program Act in 1978. This program fostered new climate institutions, enhanced applied research, and funded new data collection-transmission systems. However, at the federal level the program became overshadowed in the late 1980 s by the rapidly expanding national climate change endeavors.

Concerns over a climate change related to global warming became a new thrust enveloping most of the atmospheric sciences. An era of numerous weather extremes and large global losses during the 1990s has led applied climatologists to pursue climatological assessments (Changnon, 1999a, 1999b). Some have assessed whether these increasing losses were due to the start of a climate change due to global warming, to increasing societal vulnerability to climate (Changnon et al. 2000), and/or to inadequate government policies (Changnon 
and Easterling 2000). Recent major urban droughts in the U.S. initiated new societal problems, indicating to urban leaders that future water supplies for their major urban areas are questionable and need climate data to be improved (Changnon 2000).

Development during the 1960s and 1970s of reasonably inexpensive computer systems capable of handling large volumes of climate data was another key factor in the recent growth in climate services. The systems allow continual updates of information and the development and near real-time delivery of climate information, coupled with wide use of PCs. Everyone can now access a wealth of climate information quickly and at low cost (Kunkel et al. 1990). This has greatly enhanced the use of climate information, and in turn, has created greater awareness of the value of climate information.

The above-mentioned fast access was facilitated by another technological step forward-the development of inexpensive means to quickly collect data, and to transmit climate data and information. This included satellites and the Internet. These allowed real-time transmittal of data and quick access to it, a huge step forward (Changnon and Kunkel 1999). Closely coupled with this advance were the establishment of new climate service/research centers, which had been fostered by the National Climate Program (Changnon et al. 1990), as well as the growth of private sector providers of climate information (Vogelstein 1998). The development of these new institutions with expertise and systems to serve the needs of users of climate data and information led to other advances in climate services.

Interdisciplinary research by climatologists and other physical and social scientists has increased in recent years, and this has led to a new level of sophisticated climate-effect models (crops, water, transportation, etc.). Further, these models, when fed with real-time data, allow their use in operational settings. Thus, near real-time estimates of current and projected climate effects can be generated for decision makers. These activities moved forward in the right arenas based on assessments of user needs that began during the $1970 \mathrm{~s}$, a form of market analysis for climate products (Changnon et al. 1988; Changnon 1992).

The nation and world have seen an increase in society's sensitivity to climate conditions and especially to climate extremes in recent years. Population growth, coupled with demographic changes and greater wealth, have created greater vulnerability in the U.S., and hence, higher costs when climate anomalies occur. These impacts in the U.S. have fufther promoted the growth in the use of climate data and information to more effectively react, manage, and compete (Stern and Easterling 1999). Climate information has taken on greater value. One reflection of this in the business world has been the development and use of "weather derivatives" during the 1990s, a means of insuring against climatological risk (Zeng 2000). One company offers coverage for a fixed price against a climate outcome, say a cold winter, that a utility fears economically. If the cold winter occurs, the coverage firm pays the other for its losses, but if the cold winter does not occur, the coverage firm retains the original payment. Such risks are assessed and outcomes are decided using climate data.
One of the climate products long sought by weather-sensitive entities has been accurate longterm climate predictions. The past 20 years have seen major advances in climate prediction quality, related to a greater understanding of the climate system such as the effects of El Nino on the nation's climate (Kousky and Bell 2000). Governmentissued predictions have improved, both in accuracy and formats needed by users (Changnon et al. 1995). Private firms now work more closely with firms to interpret predictions to meet specific corporate needs, all a part of the growth in the private sector involved in climate services.

\section{A Bright Future and Issues Needing Attention to Optimize Climate Services}

Climatology has moved to a high level of service to society. Achieving an even greater level of wise usage of climate information faces a few issues needing attention and resolution.

The teaching of service-oriented applied climatology remains too limited and often is not done at many colleges and universities with atmospheric sciences programs. Quality instruction in applied, service-oriented climatology requires interdisciplinary training and experience (Changnon, D. 1998).

A second issue relates to the adequacy of weather instrumentation and data collection. Since the structure of weather data collection endeavors in the U.S. is still dominated by the needs of forecasters, there are continuing problems with sustaining adequate spatial sampling of climate conditions and with the use instruments that allow continuity with historical data (NRC 1998). For example, the automated surface observation system installed during the 1990s for measuring weather conditions at the nation's first-order weather stations led to serious alterations in the quality of certain data.

As noted, the use of climate data and information has grown rapidly in the past 40 years, but sampling reveals many potential users are still not served and often unaware of applications (Changnon and Changnon 2003). An outreach effort by government agencies involved in climate services, and by private sector partners, is needed to educate and demonstrate further how to use climate information and the potential values apt to be realized from usage to manage climate risks (Changnon 2004).

A fourth issue relates to the lack of a systematic collection of data on the impacts of climate extremes. A national effort to begin such data collection is needed (NRC 1999).

A fifth issue is the uncertainty over impacts under a changing future climate due to global warming. It is a current dilemma and one that will continue. Hare (1985) first noted the need to consider impacts of future climate change. Some have predicted future climate conditions exceed extremes sampled in the past 100 years, making use of existing climate-impact regression models as predictors of future impacts invalid. The implications of future climate changes remain a major challenge for climatologists. This is reflected in a recent book about applied climatology which 
includes four chapters addressing potential impacts of future climate change (Thompson and Perry 1997).

Resolution of these five issues: better training, stabilization of weather measurements, enhanced outreach to users, better information about climate impacts, and effects of global climate change is needed if we are to realize the full potential of climate services. Regardless, climatology is the oldest atmospheric sciences activity in service to society and is its most successful.

\section{Summary}

Climatological data and information have been the foundation upon which the nation's weathersensitive activities and infrastructure have been developed over the past $200+$ years. In recent years, the use of climate information has moved to a new level of recognition and ever higher value to climatesensitive sectors of the nation. Recent decades have seen a series of scientific and technological changes that have vastly enhanced the use of climate information. Atmospheric scientists created major improvements in weather-sensing instruments, in data quality and its archival, in the ease of accessing of data and climate information, and in the generation of user-friendly climate products. Coupled with these major advances have been national and global economic conditions and government policies that have collectively acted to increase greatly the demand for climate products. To serve these needs, we have seen government establishment of state climatologists in all states, a national network of six regional climate centers, and an enhanced national data center. On the private business side, there has been a rapid expansion of firms providing climate services, now bringing new climate-based products to a vast array of climatesensitive businesses and government agencies.

The notable accomplishments attributed to use of climate data and information provide a large foundation for the future. Climate services have come a very long way and are ready to address their few remaining challenges.

\section{Acknowledgments}

Many have contributed to the field and its recent progress. My life-long involvement in climate services has greatly benefitted from support of many persons. The guidance of Helmut E. Landsberg and Floyd A. Huff has been extremely important to my interest in service-oriented climatology. I have also benefitted from knowing and working with several of the major contributors to the field including Dave Hershfield, Jim McQuigg, Ken Hare, Max Kohler, Arnold Court, Bob Kates, Wayne Palmer, and Louie Thompson. Water Survey staff have been helpful in many ways including Bill Easterling, Ken Kunkel, Wayne Wendland, and Jim Angel.

\section{References}

Brooks, C.F. 1925. The cooling of man under various weather conditions. Mon. Wea. Rev. 53: $28-33$.

Changnon, D. 1998. Design and test of a "hands-on" applied climate course in an undergraduate meteorology program. BAMS 79: 79-84. Changnon, S. A. 1973. Atmospheric alterations from man-made biospheric changes. In Weather Modification: Social concerns and Public Policies. Western Geographical Series: 134-184.

Changnon, S.A. 1979. What to do about urbangenerated weather and climate changes. Journal American Planning Association 45: $36-48$.

Changnon, S.A. 1981. The American Association of State Climatologists. BAMS 62: 620-622.

Changnon, S.A. 1984. Purposeful and accidental weather modification: Our current understanding. Physical Geography, 4: 126139.

Changnon, S.A. 1992. Contents of climate predictions desired by agricultural decision makers. J. Applied Met. 31: 1488-1491.

Changnon, S.A. 1998. Review of economic value of weather and climate forecasts. BAMS 79: 470-471.

Changnon, S.A. 1999a. Factors affecting temporal fluctuations in damaging storm activity in the U.S. based on insurance loss data. Meteorological Applications 6: 1-11.

Changnon, S.A. 1999b. Record high losses for weather hazards during the 1990s: How excessive and why? Natural Hazards 18: 287-300.

Changnon, S.A. 2000. Reactions and responses to recent urban droughts. Physical Geography 21: $1-20$.

Changnon, S.A. 2004. Changing uses of climate predictions in agriculture: Implications for prediction research, providers, and users. Weather and Forecasting 19: 606-613.

Changnon, S.A. 2007. New risk assessment products for dealing with financial exposure to weather hazards. Natural Hazards 26: in press.

Changnon, S.A. Sonka, S. and S. Hofing, 1988. Assessing climate information use in agribusiness. Part 1: Actual and potential use and impediments to use. J. Climate 1: 757-765.

Changnon, S.A., Lamb, P., and K. Hubbard, 1990. Regional climate centers: New institutions for climate services and climate impact records. BAMS 71: 527-537.

Changnon, S.A., Changnon, J., and D. Changnon, 1995. Assessment of uses of climate forecasts in the utility industry in the central U.S. BAMS 76: 711-720.

Changnon, S.A., and K. E. Kunkel, 1999. Rapidly expanding uses of climate data and information in agriculture and water resources. BAMS 80: 821-830.

Changnon, S.A., Pielke, R.A., Changnon, D., Sylves, R. and Pulwarty, R. 2000. Human factors explain the increased losses from weather and climate extremes. BAMS 81: 437-442.

Changnon, S.A., and D.R. Easterling, 2000. U.S. 
policies pertaining to weather and climate extremes. Science 289: 2053-2055.

Changnon, D. and S. Changnon, 2003. Assessment of issues related to usage of climate predictions in the U.S. agribusiness sector and utility industry. Proceedings Workshop on Climate Predictions, Amer. Met. Soc. Washington, DC.

Conrad, V., and L. Pollack, 1944. Methods in Climatology. Harvard University Press. Boston, MA.

Court, A. 1949. Separating frequency distributions into normal components. Science 110: 500510.

Fleming, J. R. 1990. Meteorology in America, 18001870. Johns Hopkins University Press. Baltimore, MD.

Flora, S.D. 1953. Tornadoes of the U. S. University of Oklahoma Press. Norman, OK.

Hare, K.F. 1985. Future environments - can they be predicted? Transactions, Institute of British Geographers 10: 131-137.

Hershfield, D.M. 1961. Rainfall Frequency Atlas of the U.S. Weather Bureau. Washington, DC.

Horton, R.E. 1927. On the Hydrology of the Great Lakes. Engineering Board of Review. Sanitary District of Chicago, Chicago, IL.

Huff, F.A. 1986. Urban hydrometeorology review. BAMS 67: 703-711.

Jacobs, W. C. 1947. Wartime development in applied climatology. Met. Monog. 1(1): 152.

Kates, R. W. 1980. Climate and society: lessons from recent events. Weather 35: 17-25.

Koeppen, W. 1885. Zur Charaskteristik der regen in NW Europa and Nordaamerika. Met. Z:. 1024.

Kousky, V.E., and G.D. Bell, 2000. Causes, predictions, and outcomes of El Niño 19971998. In El Niño 1997-1998, the Climate Event of the Century. Oxford Press. New York. 28-48.

Kunkel, K.E., Changnon, S.A., Lonnquist, C., and J.R. Angel, 1990. A real-time climate information system for the Midwestern U.S. BAMS 71: 601-609.

Landsberg, H. 1946. Climate as a natural resource. Scientific Monthly 63: 293-298.

Landsberg, H. 1956. The climate of towns. Mans Role in Changing the Face of the earth, University of Chicago Press. Chicago, IL.

Landsberg, H., and W. C. Jacobs, 1951. Applied climatology. In Compendium of Meteorology, T. F. Malone (ed.). Boston: Am. Met. Soc. pp. 976-992.

Linsley, R.K., Kohler, M. and J. Paulhus, 1958. Hydrology for Engineers. McGraw-Hill. New York, NY.
Martin, E.T. 1952. Thomas Jefferson: Scientist. H. Schuman. New York, NY.

Maunder, W.J. 1970. The Value of the Weather. Methuen. London.

McQuigg, J.D. 1974. The use of meteorological information in economic development. Applications of Meteorology to Economic and Social Development. World Meteorological Organization Tech. Note 132: 7-59.

National Research Council, 1998. Future of the National Weather Service Cooperative Network. National Academy Press. Washington, DC.

National Research Council, 1999. The Costs of Natural Disasters. A Framework for Assessment. National Academy Press. Washington, DC.

Oliver, J. E. 1973. Climate and Man's Environment. An Introduction to Applied Climatology. Wiley. New York.

Oliver, J. E. 1981. Climatology: Selected Applications. Wiley. New York.

Palmer, W.C. 1965. Meteorological Drought. U.S. Weather Bureau Research Paper 45, Washington, DC.

Panel on the Effective Use of Climate Information in Decision Making, 1981. Managing Climatic Resources and Risks. National Academy Press. Washington, D.C.

Stern, P. and W. Easterling, 1999. Making Climate Forecasts Matter. National Academy Press. Washington, DC.

Thiessen, A.H. 1912. Using weather data in engineering problems. Mon. Wea. Rev. 40: 1565-1567.

Thompson, L.M. 1964. Our recent high yields-how much due to weather? Research in Water, Soil Society of America, 74-84.

Thompson, R.D., and A. Perry, 1997. Applied Climatology Principles and Practice. Routledge Press. New York, NY.

Thornthwaite, C. W. 1937. The hydrologic cycle reexamined. Soil Conservation, 3: 85-91.

Wallace, H.A. 1920. Mathematical inquiry into the effect of weather on corn yields in the eight corn belt states. Mon. Wea. Rev. 48: 439446.

Whitnah, D. 1961. A History of the U.S. Weather Bureau. University of Illinois Press. Urbana, IL.

Vogelstein, F. April 13, 1998. Corporate America loves the weather. U.S. News \& World Report, 48-50.

Zeng, L. 2000. Weather derivatives and weather insurance: Concept, application, and analysis. BAMS 81: 2075-2082. 